\title{
Numerical Investigation of Drone Strikes with Various Aircraft Targets
}

\author{
Florian Franke ${ }^{1,2}$, Thomas Slowik2 ${ }^{2}$ Uli Burger ${ }^{2}$, Christian Hühne ${ }^{1,3}$ \\ ${ }^{1}$ TU Braunschweig, Universitätsplatz 2, 38106 Braunschweig, Germany \\ ${ }^{2}$ TH Ingolstadt, Esplanade 10, 85049 Ingolstadt, Germany \\ ${ }^{3}$ Deutsches Zentrum für Luft- und Raumfahrttechnik, Lilienthalplatz 7, 38108 \\ Braunschweig, Germany
}

\begin{abstract}
Small unmanned aerial vehicles are an increasing threat for manned aviation. There is a risk of a mid-air collision between such drones and manned aircraft. Within this paper, drone strikes with various aircraft targets are investigated with numerical simulations. Drone strikes on wing leading edges and helicopter windscreens are simulated. The simulations are performed with the explicit solver Radioss. The FE models of the targets as well as the drone are described in detail. The results show that both drone and target structure suffer severe damage. It depends on the point of impact how severe the damage is. The penetration speed of the windshield is between $85 \mathrm{~m} / \mathrm{s}$ and $90 \mathrm{~m} / \mathrm{s}$. We determine worst-case impact scenarios and discuss, how the target structure may sustain such damage. In this worst-case scenario, a doubling of the windshield is needed to withstand a drone strike. In the case of impacts on wing leading edges, the damage depends strongly on the location. The central impact on a rib shows less damage than the impact between two ribs. From impacts with a speed of $80 \mathrm{~m} / \mathrm{s}$ onwards, it must be assumed that the airworthiness of the target aircraft is strongly affected.
\end{abstract}

\section{Introduction}

Small unmanned aerial vehicles (sUAV) are increasingly becoming the focus of public attention due to their wide range of applications. UAVs are used for photos and videos, farming, deliveries, surveillance and further activities. With the increasing use of UAVs or so-called "drones", the risk of a drone strike between unmanned and manned aircraft increases [1]. As current aircraft structures are only designed to withstand bird strikes, drone strikes pose a new threat to manned aviation. Therefore, in this paper we perform a numerical investigation of the impact of typical quadcopter drones on various manned aviation target structures with the explicit finite element (FE) solver Radioss. Both a generic wing leading edge and the windshield of a Blackhawk helicopter are studied as target structures. In September 2017, there was a mid-air collision between a DJI Phantom 4 quadcopter and a UH-60M Blackhawk helicopter [2]. While the helicopter had only minor damage to the window frames and rotor blades, the UAV was completely destroyed. This accident confirms the relevance of the topic. The question arises as to what would have happened if the drone had hit the helicopter windshield frontally. Furthermore, it must be investigated what effect an impact of a drone has on other aircraft structures, e.g. wing leading edges (WLE).

The issue of collision of drones with aircraft structures is already being researched. A first study about the damage potential of drones was published by the Civil Aviation Safety Authority (CASA) in 2013 [3]. They concluded that the airframe of a commercial aircraft will penetrate if a drone hits the structure with impact speeds larger than $103 \mathrm{~m} / \mathrm{s}$. One of the fundamental reports about drone strikes was published by ASSURE (Alliance for System Safety of UAS through Research Excellence) [4-7]. On the basis of their numerical results they conclude, that a drone strike produces more damage than a bird strike for the same kinetic energy. Further authors like Song and Schroeder [8-11], Man et 
al. [12], Schwab [13], Lyons et al. [14], Yu et al [15], Hou et al. [16] as well as Liu et al. [17] investigated the impact of drones with engines. Together, these studies show that the ingestion of a drone will lead to severe damage within the ingestion, especially in the area of the fan. Very little is currently known about drone strikes with helicopters. Che Man et al. [18] as well as Jonkheijm [19] performed numerical investigations with helicopter windshields. Che Man used a very simple windshield model. On the other hand, the material data used by Jonkheijm are questionable since they are very large and his results show a very brittle behavior. Ritt et al. [20] published an investigation of a drone strike on a helicopter canopy demonstrator. Material data of the models are not published in this study. Drone strikes with fixed wing aircraft structures have been more in focus so far. Among others, Dadouche et al. [21], Meng et al. [22] as well as Lu et al. [23] conducted impact tests and validated their finite element models against these data. Further authors like Wang et al. [24], Drumond et al. [25, 26] and Warsiyanto et al. [27] have only performed numerical analyses of drone strikes with aircraft structures.

Two research gaps emerge from the literature review. First, the drone strike on a helicopter windshield with a precise modeling approach needs to be investigated. Second, the question arises whether damage to various aircraft structures can be reduced by varying drone parameters, e.g. impact velocity or flight orientation. These issues are explored in this paper. For this purpose, the FE models are presented in the following chapter. Chapter 3 will show and discuss the results.

\section{FE Models of Target and Projectile}

This study uses the finite element method (FEM) to analyze drone strikes with a WLE and a windshield. FE models are created of both the targets and the projectiles. This chapter describes the used FE and material models. Hypermesh 2017 is used as the pre-processor to create the models. The explicit solver Radioss 2017 is used for calculations and post-processing is done with Hyperview 2017.

\section{A. Wing Leading Edge (WLE)}

Figure 1 shows the FE model of a generic wing leading edge (WLE), its boundary conditions and its dimensions. The leading edge of the wing is modelled up to the first spar without the wing box. The model consists of three parts: skin, ribs and spar. It has a length of $1500 \mathrm{~mm}$. The ribs are parabolic with a width and height of $400 \mathrm{~mm}$ each. There are five ribs along the model with a distance of $375 \mathrm{~mm}$. The material of the skin is aluminum A12024-T3 with a thickness of $\mathrm{h}=1.6 \mathrm{~mm}$. We use the Johnson-Cook material model for Al2024-T3. Ribs and the spar are composed out of aluminum A17075-T7451 with an elasto-plastic material model. The ribs have a thickness of $\mathrm{h}=2.0 \mathrm{~mm}$, the spar has a thickness of $\mathrm{h}=3.5 \mathrm{~mm}$. All elements are fully integrated shell elements to avoid hourglassing. The skin is connected to the ribs via rivets (connector elements). A fixed clamping of the rear edge is modelled. A "Type 7" general contact is used to model the contact between the components. The whole WLE consists out of 426945 shell elements and 428830 nodes. Two impact locations are investigated, the central impact on a rib and the impact between two ribs. Furthermore, two flight orientations are studied, shown in Figure 2. Four impact speeds are studied: $20 \mathrm{~m} / \mathrm{s}$, $80 \mathrm{~m} / \mathrm{s}, 100 \mathrm{~m} / \mathrm{s}$ and $150 \mathrm{~m} / \mathrm{s}$.

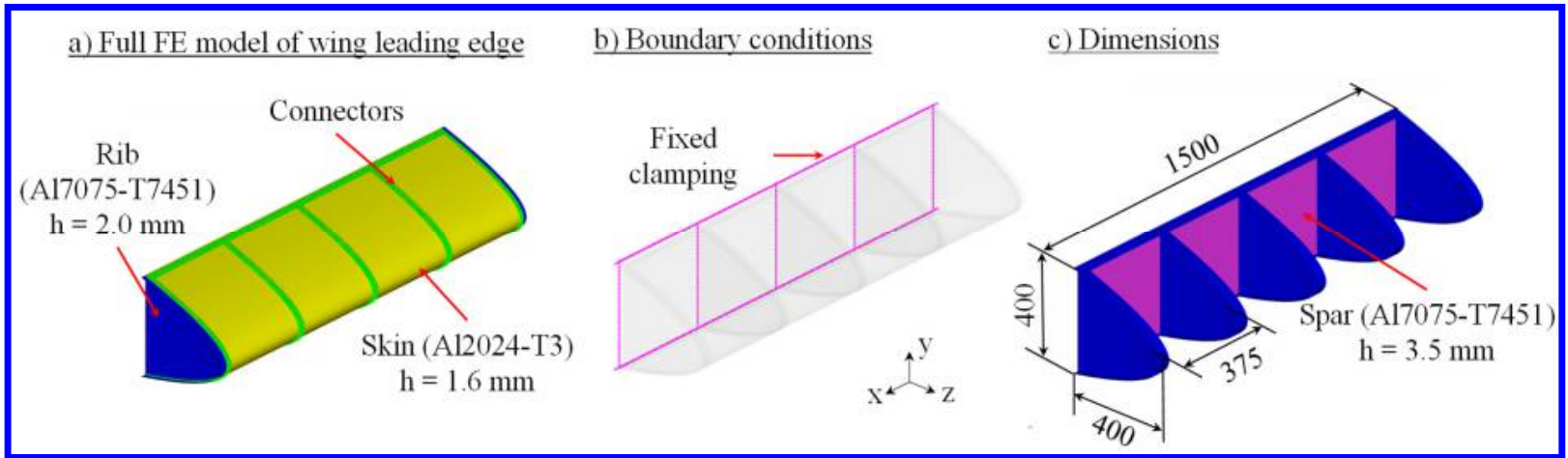

Figure 1: a) FE model of wing leading edge; b) Boundary conditions; c) Dimensions 


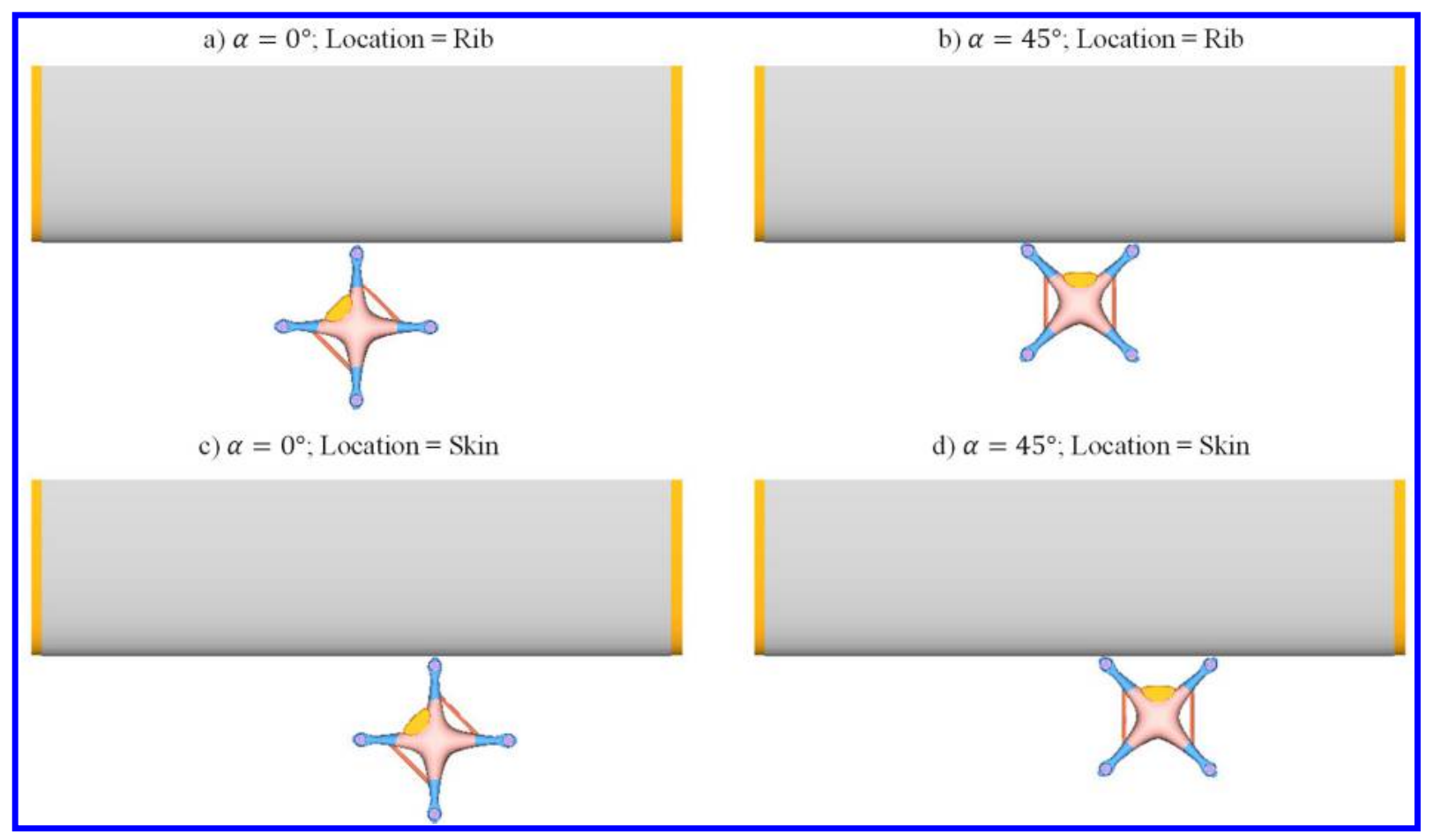

Figure 2: Impact locations and configurations

The Johnson-Cook model with damage initiation (M2 in Radioss) is used for A12024-T3 with data from [28] whereas A17075-T6 is described with an elastic-plastic piecewise linear material model (M36 in Radioss) with data from [29]. The material data are shown in Table 1 and Table 2.

Table 1: Material data for Al2024-T3 (Johnson-Cook) [28]

\begin{tabular}{|c|c|c|c|c|c|c|c|c|c|c|}
\hline & $\begin{array}{c}\text { Density } \\
\rho\left[\mathrm{kg} / \mathrm{m}^{3}\right]\end{array}$ & $\begin{array}{l}\text { Young's modulus } \\
E[\mathrm{MPa}]\end{array}$ & Pois & ratio & $\begin{array}{c}a \\
{[\mathrm{MPa}]}\end{array}$ & $\begin{array}{c}b \\
{[\mathrm{MPa}]}\end{array}$ & $\begin{array}{c}n \\
{[-]}\end{array}$ & $\begin{array}{c}c \\
{[-]}\end{array}$ & $\begin{array}{l}m \\
{[-]}\end{array}$ & $\begin{array}{l}\dot{\varepsilon}_{0} \\
{[-]}\end{array}$ \\
\hline \multirow[t]{3}{*}{ Al2024-T3 } & 2770 & 73000 & & & 369 & 684 & 0.73 & 0.0083 & 1.7 & 1 \\
\hline & & $D 1$ & $D 2$ & D3 & & $D 4$ & $D 5$ & & & \\
\hline & Al2024-T3 & 0.112 & 0.123 & -1.5 & & .007 & 0 & & & \\
\hline
\end{tabular}

Table 2: Elastic-plastic piecewise linear material model [29]

\begin{tabular}{ccccccc}
\hline & $\begin{array}{c}\text { Density } \\
\rho\left[\mathrm{kg} / \mathrm{m}^{3}\right]\end{array}$ & $\begin{array}{c}\text { Young's modulus } \\
E[\mathrm{MPa}]\end{array}$ & $\begin{array}{c}\text { Poisson's ratio } \\
v[-]\end{array}$ & $R_{\mathrm{p} 02}[\mathrm{MPa}]$ & $R_{\mathrm{m}}[\mathrm{MPa}]$ & $\varepsilon_{\max }[-]$ \\
\hline A17075-T6 & 2796 & 71016 & 0.33 & 476 & 538 & 0.09 \\
\hline
\end{tabular}

\section{B. Windshield}

The second model is a helicopter windshield model. This model is based on the Sikorsky UH-60 Black Hawk Helicopter geometry. The main difference of various modeling setups is the applied abstraction scale in discretization. The possibilities of a layered-shell approach and two models with stacked layers are analyzed. The replacement model 
of the Sikorsky UH-60 Black Hawk windshield can be modeled by its layered structure, consisting of two PMMA layers and an intermediate adhesive layer, as a single layer of elements representing the entire overall structure as a laminate stack. This method applies shell elements to capture the bending behavior of the laminate with a single layer of elements. In addition, using at least one integration point per layer ensures that the stresses and strains of each layer can be derived. Figure 3a) shows the layered-shell approach. In the next step, the meshing of the individual layers of the windshield is modeled by at least one layer of elements. This so-called stacked approach is modeled with both volume and shell elements. Adjacent layers share neighboring nodes and their degrees of freedom at the contact surfaces are coupled. This approach may be used either with solid or shell elements. Figure 3b) shows the stackedsolid model and Figure 3c) the stacked-shell model. The stacked-solid model has one element layer of solid elements for each layer of the windshield. The stacked-shell model, on the other hand, consists of two element layers with shell elements and an adhesive layer of solid elements in between. The consideration of the simulation results of the prestudy is done in terms of damage behavior, computation time and modeling effort.

a) Layered-Shell

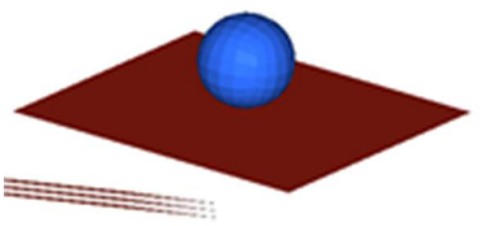

b) Stacked-Solid

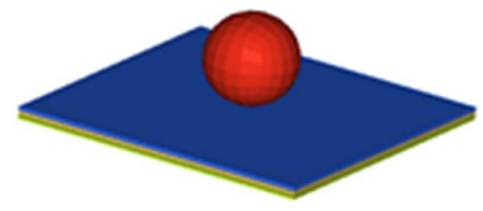

c) Stacked-Shell

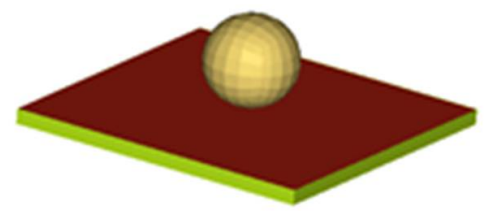

Figure 3: Preliminary investigation for windshield modeling

We assume that the windshield consists out of acrylic glass. The brittle material model M27_PLAS_BRIT is used in Radioss to describe the behavior of this material. Between two acrylic glass layers is an adhesive layer made of polyvinylbutyral (PVB). The M59_CONNECT material model is used for the adhesive layer. All material model values are shown in Table 3.

Table 3: Material data for windshield model [30, 31]

\begin{tabular}{ccccccc}
\hline & Density & Young's modulus & Poisson's ratio & Yield stress & Hardening & max. Strain \\
& $\rho\left[\mathrm{kg} / \mathrm{m}^{3}\right]$ & $E[\mathrm{MPa}]$ & $v[-]$ & $\sigma_{\mathrm{y}}[\mathrm{MPa}]$ & $\beta[-]$ & $\varepsilon[-]$ \\
\hline Acrylic glass & 1180 & 3000 & 0.4 & 60 & 0.5 & 0.025 \\
PVB & 1100 & 530 & 0.485 & 11 & - & - \\
\hline
\end{tabular}

In the analysis of damage initiation and propagation, the stacked-shell model shows the most accurate results compared to the other models. It is noticeable that the stacked-shell model underestimates the damage, whereas the stacked-solid model predicts a larger damage range, since it is the only one that takes the relevant out-of-plane stress component into account. When investigating the computational and modeling effort, as expected, is significantly lower for a layered-shell model compared to the stacked-layer approaches. Due to the smaller number of degrees of freedom (DoF), the stacked-shell model is $50 \%$ faster to complete compared to the stacked-solid model. Finally, we see a significant difference in the maximum displacement in z-direction for the layered-shell and the two stacked approaches. The layered-shell model shows a maximum deflection of $u=3.76 \mathrm{~mm}$ whereas the stacked models have a maximum deflection in $\mathrm{z}$-direction of $\mathrm{u}=7.01 \mathrm{~mm}$ each (Figure 4 ).

Table 4 presents the results of the comparison of the different modelling approaches. For these reasons, the stackedshell approach is chosen as the basis for this work. Based on the stacked-shell approach, the windshield of the Sikorsky UH-60 Black Hawk transport helicopter is modeled and meshed using CAD files from an online CAD database (see Figure 5). The model consists of two shell element layers bonded together by a solid layer of cohesive elements. The thickness of the windshield is $6 \mathrm{~mm}$ and the element size of the mesh is $5 \mathrm{~mm}$. In first investigations, the edge of the windscreen is assumed to be fixed clamped in place. 


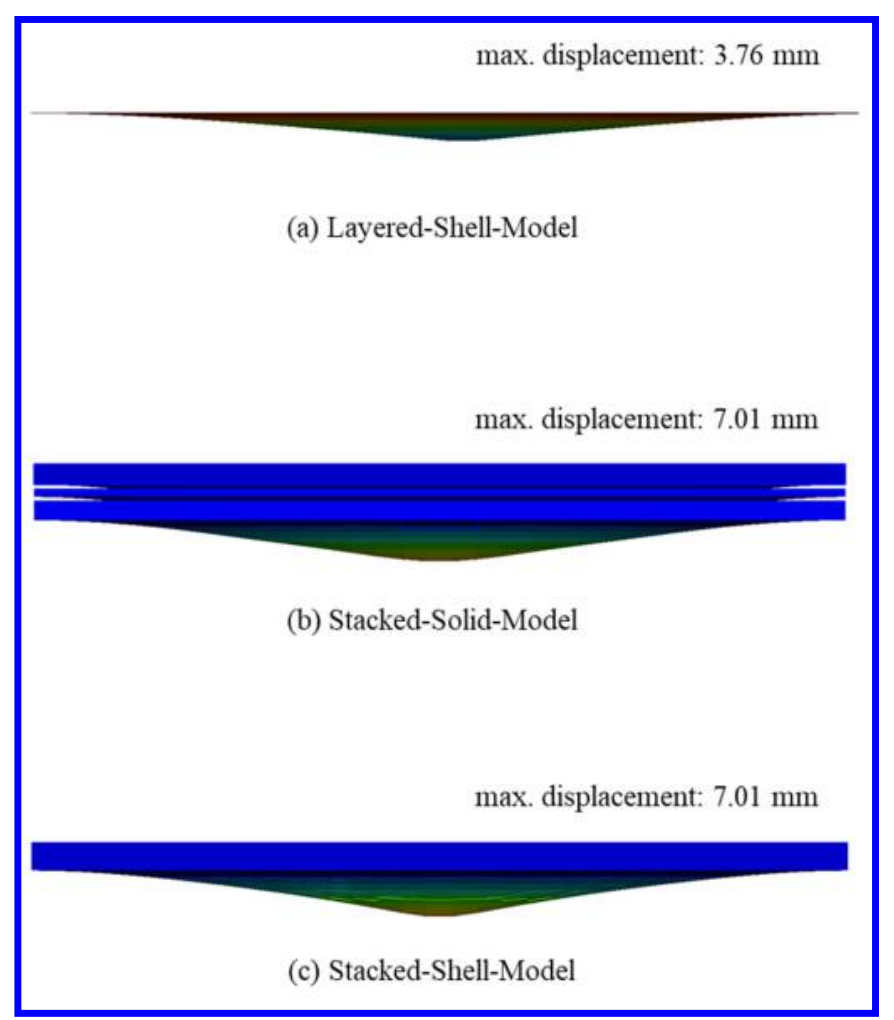

Figure 4: Deformations of various modeling approaches

Table 4: Summary of the evaluation criteria for the modelling approaches

\begin{tabular}{cccc}
\hline & Layer-Shell & Stacked-Solid & Stacked-Shell \\
\hline Deformation & - & ++ & ++ \\
Damage & $\mathrm{o}$ & ++ & + \\
Modelling effort & ++ & -- & $\mathrm{o}$ \\
Numerical effort & ++ & $\mathrm{o}$ & + \\
\hline
\end{tabular}

a) Windshield model

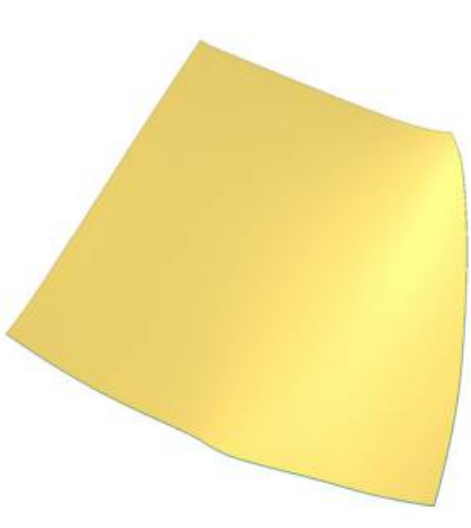

b) Boundary conditions

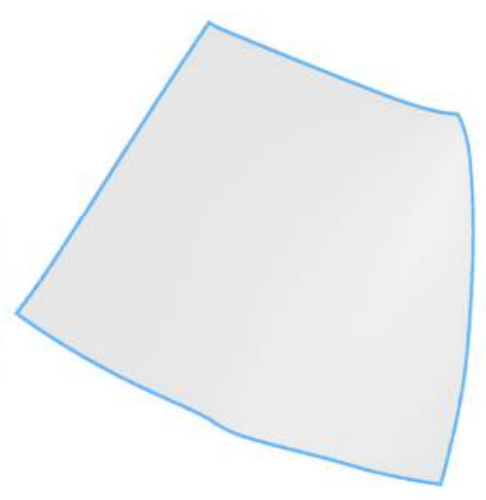

c) Stacked shells modelling approach

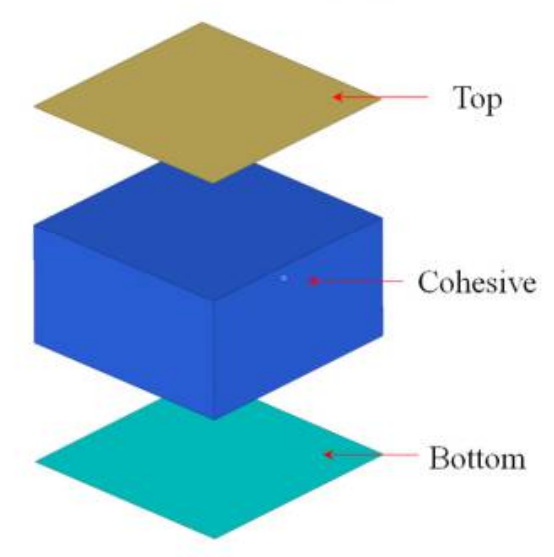

Figure 5: a) FE model of helicopter windshield; b) Boundary conditions; c) Modelling technique 


\section{SUAV Model}

We use a simplified FE model of a DJI Phantom 4 quadcopter, as this UAV is often used by non-professionals (see Figure 6). The Phantom 4 is one of the most sold consumer drones according to [32]. This model consists out of five different components: 4 x Motors, battery, top- and bottom shell, as well as landing gear. We look primarily at the motors and battery, as previous studies have found that these components can generate particularly high levels of damage. The FE models of the battery as well as that of the motors are validated against quasi-static compression test data. The rotors, the camera system, electronic systems and the inner structure are neglected. The mass of the neglected components is evenly distributed around the center of the drone. Therefore, the density of the top- and bottom shell material is increased in this area. As a result, the mass of the simplified drone model corresponds to that of a real drone. Motors as well as the battery are attached to the structure with rigid elements. To model the interaction of components, a general TYPE7 contact is used. The full drone model consists out of 272170 nodes and 223675 elements. AlMg3 and AISI 1006 are modeled with the Johnson-Cook model (Table 5). The drone model has a mass of $1380 \mathrm{~g}$.

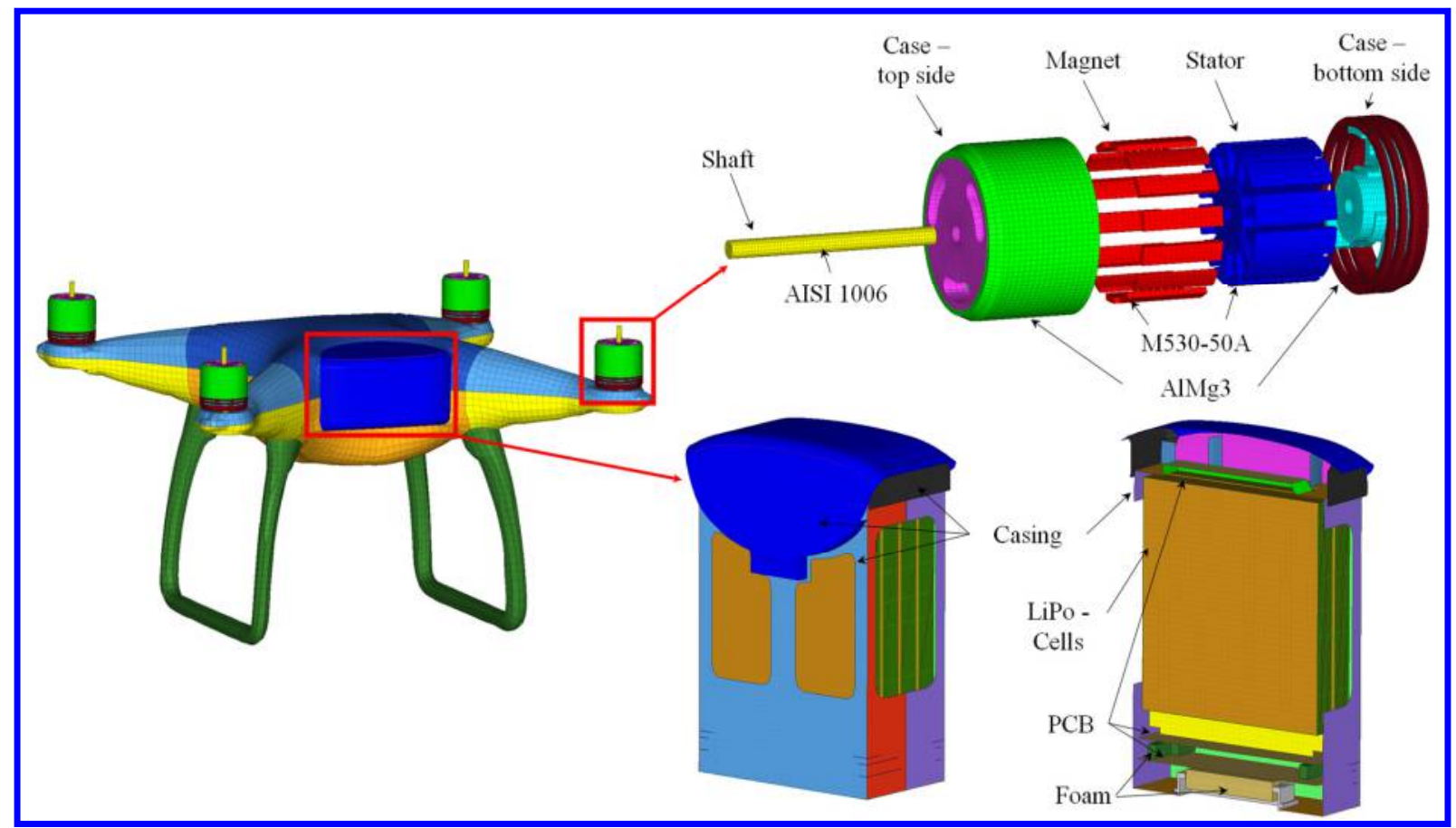

Figure 6: FE model of SUAV with detailed description of motor and battery model

Table 5: Johnson-Cook material data for AIMg3 and AISI 1006 [33, 34]

\begin{tabular}{|c|c|c|c|c|c|c|c|c|c|}
\hline & $\rho\left[\mathrm{kg} / \mathrm{m}^{3}\right]$ & $E[\mathrm{MPa}]$ & $v[-]$ & $\begin{array}{c}a \\
{[\mathrm{MPa}]}\end{array}$ & $\begin{array}{c}b \\
{[\mathrm{MPa}]}\end{array}$ & $\begin{array}{c}n \\
{[-]}\end{array}$ & $\begin{array}{c}c \\
{[-]}\end{array}$ & $\begin{array}{l}m \\
{[-]}\end{array}$ & $\begin{array}{l}\dot{\varepsilon}_{0} \\
{[-]}\end{array}$ \\
\hline AlMg3 & 2700 & 68000 & 0.3 & 28.13 & 278.67 & 0.183 & 0.00439 & 2.527 & 0.1 \\
\hline \multirow[t]{2}{*}{ AISI 1006} & 7872 & 190000 & 0.3 & 350 & 275 & 0.36 & 0.022 & 1.0 & 1 \\
\hline & & $D 1$ & $D 2$ & & 3 & $D 4$ & D5 & & \\
\hline \multicolumn{2}{|c|}{ AlMg3 } & -0.2 & 1.133 & \multicolumn{2}{|c|}{-0.229} & 0.0897 & \multicolumn{2}{|c|}{7.978} & \\
\hline \multicolumn{2}{|c|}{ AISI 1006} & -0.8 & 2.1 & \multicolumn{2}{|c|}{-0.5} & 0.002 & \multicolumn{2}{|c|}{0.61} & \\
\hline
\end{tabular}


Radioss is able to calculate parameters for the Johnson-Cook model out of yield strength, tensile strength and elongation at break. This option is used for M530-50A with the following values (Table 6). The materials used for the battery modeled with the elastic-plastic piecewise linear material models are polycarbonate (PC) and polyurethane. The lithium-polymer cells are modeled as a stacked pouch model with material data from Sahraei et al. [35]. The PCBs are modeled with a glass fibre G-10 orthotropic model with data from [5].

Table 6: Material values for elastic-plastic piecewise linear material model

\begin{tabular}{cccccccc}
\hline & $\rho\left[\frac{\mathrm{kg}}{\mathrm{m}^{3}}\right]$ & $E[\mathrm{MPa}]$ & $v[-]$ & $R_{\mathrm{p} 02}[\mathrm{MPa}]$ & $R_{\mathrm{m}}[\mathrm{MPa}]$ & $\varepsilon_{\max }[-]$ & Source \\
\hline M530-50A & 7700 & 210000 & 0.3 & 295 & 430 & 0.89 & {$[36]$} \\
PC & 1200 & 2350 & 0.3 & 62 & 62 & 0.2 & {$[22]$} \\
$\begin{array}{c}\text { Polyurethane } \\
\text { (Foam) }\end{array}$ & 1000 & $200 *$ & 0.1 & 5 & 5 & 0.1 & {$[37]$} \\
\hline
\end{tabular}

*(adjusted to avoid numerical instabilities)

\section{Results and Discussion}

\section{A. Drone Strikes on Wing Leading Edge (WLE)}

We investigate drone strikes on the WLE and the windshield. Four impact speeds and two flight orientations are studied. Figure 7 and Figure 8 show the results for impacts on a rib and between two ribs at the time $\mathrm{t}=10 \mathrm{~ms}$. As expected, the damage increases with increasing impact velocity. We see a penetration of the drone into the WLE at a speed of $150 \mathrm{~m} / \mathrm{s}$ for both flight orientations. The $0^{\circ}$ orientation produces one hole in the impact center whereas the $45^{\circ}$ orientation produces two holes on both sides next to the centrally struck rib. Both damages may lead to catastrophic failures and a crash of the aircraft. There is no penetration for lower impact velocities. Instead, the structures show distinct plastic deformations and cracks within the skin. These damages may influence the flight characteristics of the target. Fragments of the drone are deflected along the WLE. The lowest velocity is the maximum flight velocity of the drone. In this case, the target can be assumed to be hovering or on the ground. The drone booms break away, however, the damage to the target structure is not as pronounced as for higher velocities. We only look at structures made out of aluminum in this study. If the WLE is made out of composite materials, even such a low velocity impact will produce severe damage like delaminations.

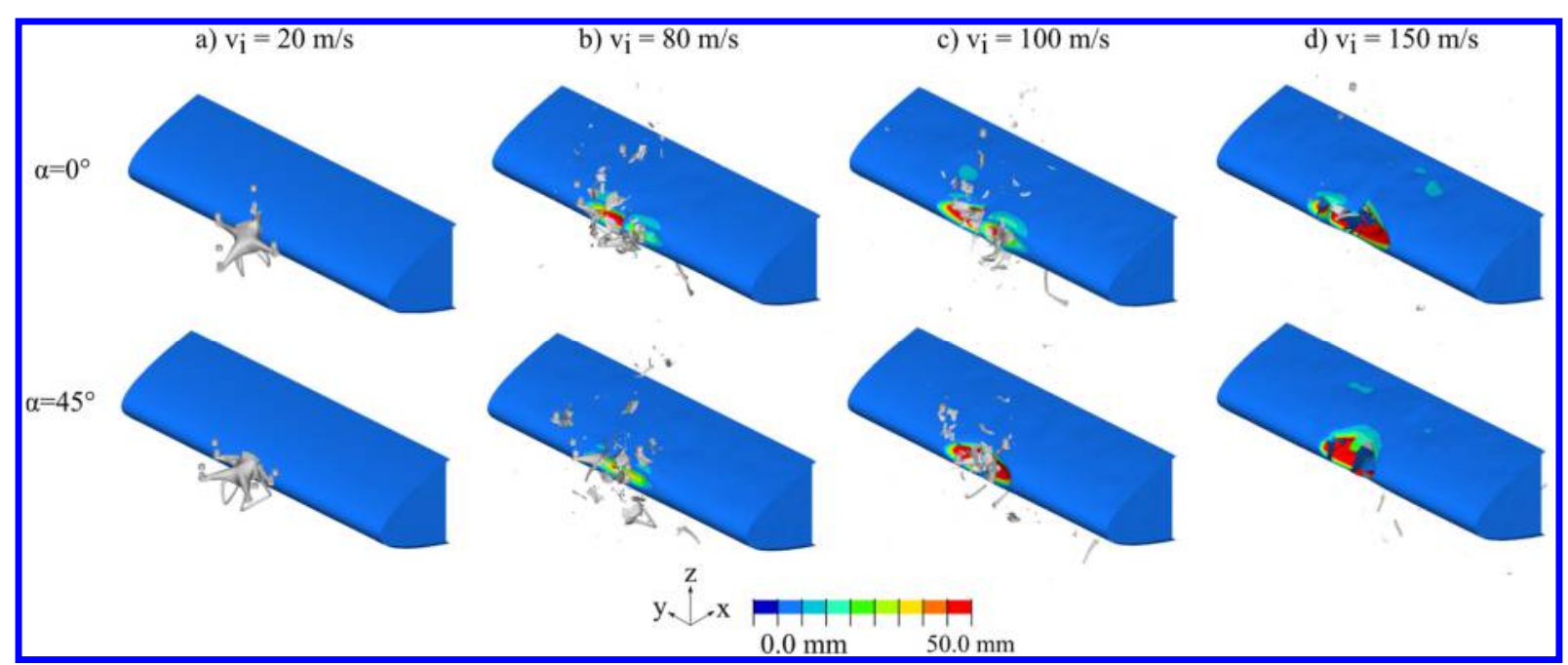

Figure 7: Drone strike on WLE (rib)

Figure 8 presents the results for drone strikes between two ribs for $0^{\circ}$ and $45^{\circ}$ flight orientation. The results also show an increase in damage with increasing impact velocity. In contrast to the impact on a rib, we see a penetration of the drone into the WLE starting at $100 \mathrm{~m} / \mathrm{s}$. This penetration is independent of the flight orientation. After this penetration, 
the drone hits the spar. At a speed of $150 \mathrm{~m} / \mathrm{s}$, the drone penetrates both, the skin and the spar for the $0^{\circ}$ orientation. With a flight orientation of $45^{\circ}$, the drone completely rips the WLE segment between two ribs. This may lead to catastrophic failure with fatal consequences for the passengers. First cracks already appear at an impact speed of $80 \mathrm{~m} / \mathrm{s}$ and an orientation of $45^{\circ}$. The produced damage is comparable to that from the University of Dayton impact tests [38]. A sUAV was shot in their tests with $120 \mathrm{~m} / \mathrm{s}$ against a Mooney M20 WLE. This impact showed large, distinct damage The drone nenetrated the skin

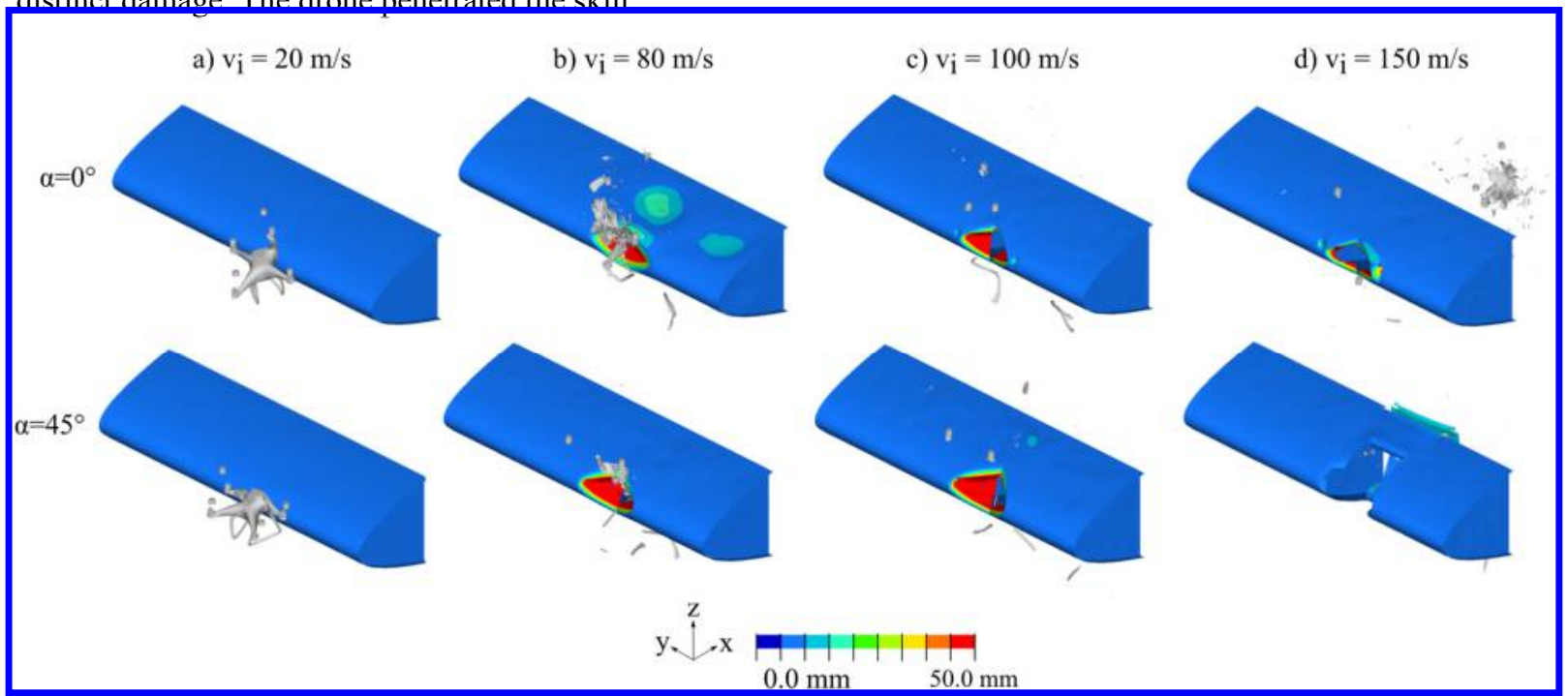

Figure 8: Drone strike on WLE (between ribs)

\section{B. Drone Strikes on Helicopter Windshields}

First drone strikes on $\mathrm{H} / \mathrm{C}$ windshields are simulated with an impact velocity of $100 \mathrm{~m} / \mathrm{s}$. Figure 9 shows the damage development of a drone strike with a $\mathrm{H} / \mathrm{C}$ windshield. The drone has a $0^{\circ}$ orientation. The landing gear of the drone is the first component that gets in contact with the windshield. It consists out of PC and induces no damage. Damage arises from $4 \mathrm{~ms}$. We see first cracks, induced by the impact of the first motor. These cracks continue to tear as the impact progresses. At the time $8 \mathrm{~ms}$, the drone has completely penetrated the windshield. Heavy and dense components like the motors, the battery, camera or other payload are able to penetrate into the cockpit und injure people.

We determine the perforation velocity with a parameter study. The impact velocity of the drone is varied for this investigation. Previous simulations show that the drone perforates the windshield at a speed of $100 \mathrm{~m} / \mathrm{s}$. Therefore, the impact speed is reduced until no more perforation occurs. The speed is reduced by steps of $5 \mathrm{~m} / \mathrm{s}$. A significant difference in terms of damage can be seen for impact velocities of $85 \mathrm{~m} / \mathrm{s}$ and $90 \mathrm{~m} / \mathrm{s}$ (see Figure 10). At a speed of $90 \mathrm{~m} / \mathrm{s}$ the drone still perforates the windshield. On the other hand, at a speed of $85 \mathrm{~m} / \mathrm{s}$, the drone is deflected along the windshield. Cracks appear at the windshield boundaries. These are modeled with a fixed clamping, which may lead to unrealistic damage behavior around the boundaries due to the unnaturally high stiffness. Nevertheless, at an impact speed of $85 \mathrm{~m} / \mathrm{s}$, the drone is not able to perforate the windshield and cannot penetrate into the cockpit. 


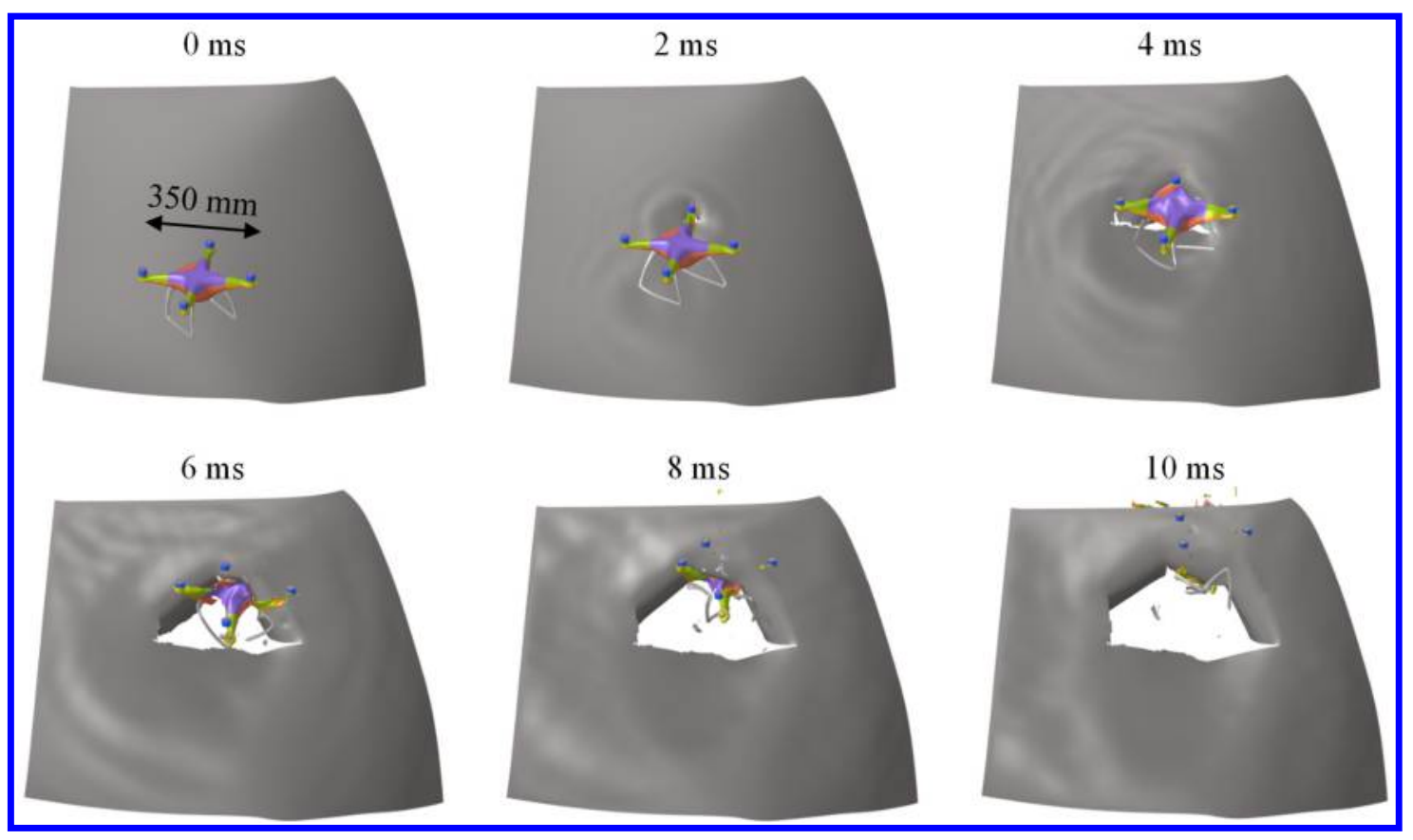

Figure 9: Damage development during impact on a $\mathrm{H} / \mathrm{C}$ windshield with $100 \mathrm{~m} / \mathrm{s}$

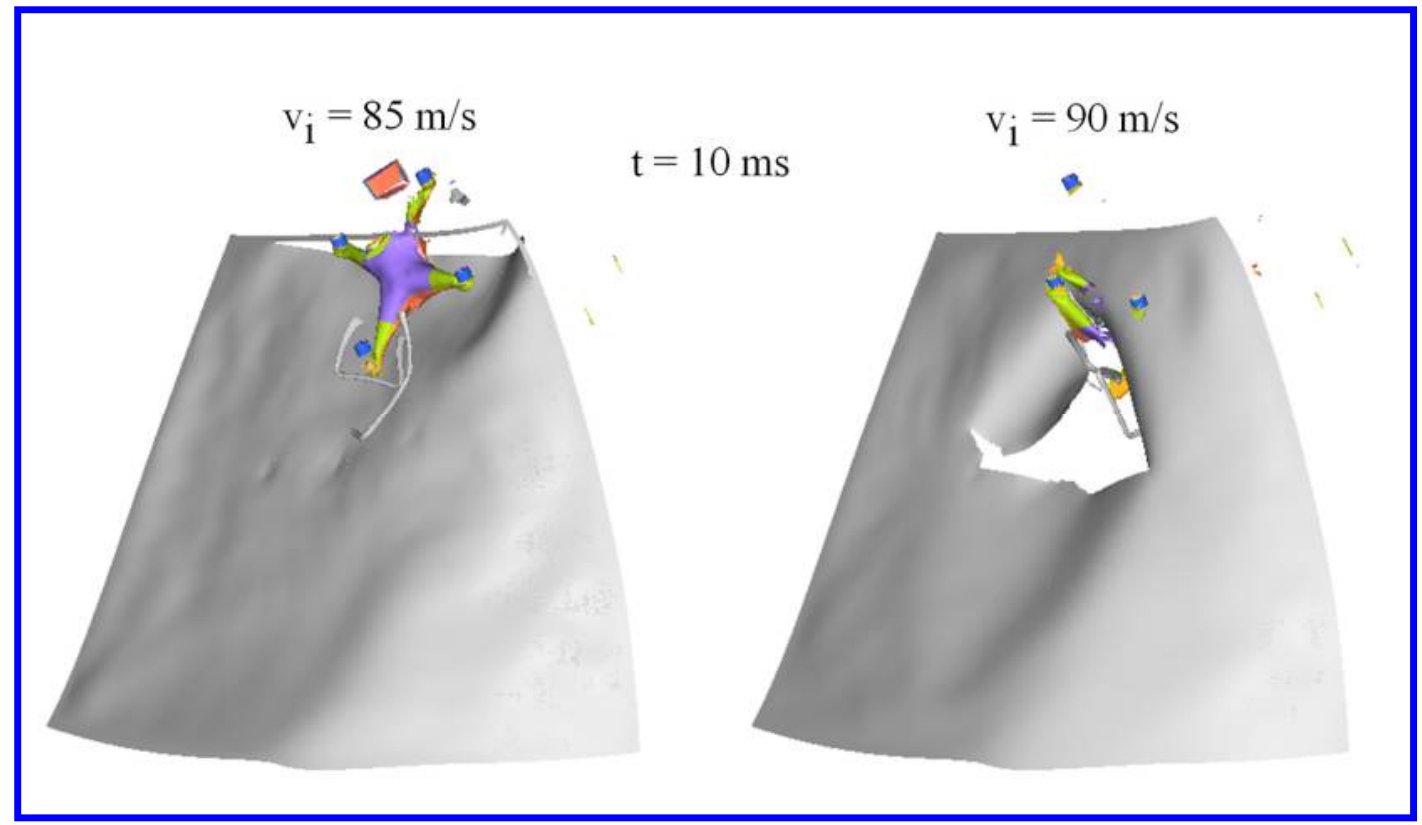

Figure 10: Determination of perforation velocity

This study shows that the boundary conditions have a significant influence on the damage and the impact behavior of the target. Therefore, one half of the helicopter cockpit is modeled to gain more realistic results, see Figure 11. A worst-case scenario is determined to investigate drone strikes on this impact level. The impact speed is $120 \mathrm{~m} / \mathrm{s}$. The drone projectile has a $45^{\circ}$ orientation, which means that two motors hit the windshield simultaneously. The outer edge of the cockpit model is fixed to a single point with rigid elements. The windshield is attached to the cockpit with rigid beam elements on the top as well as on the bottom side. The drone hits the windshield centrally. 


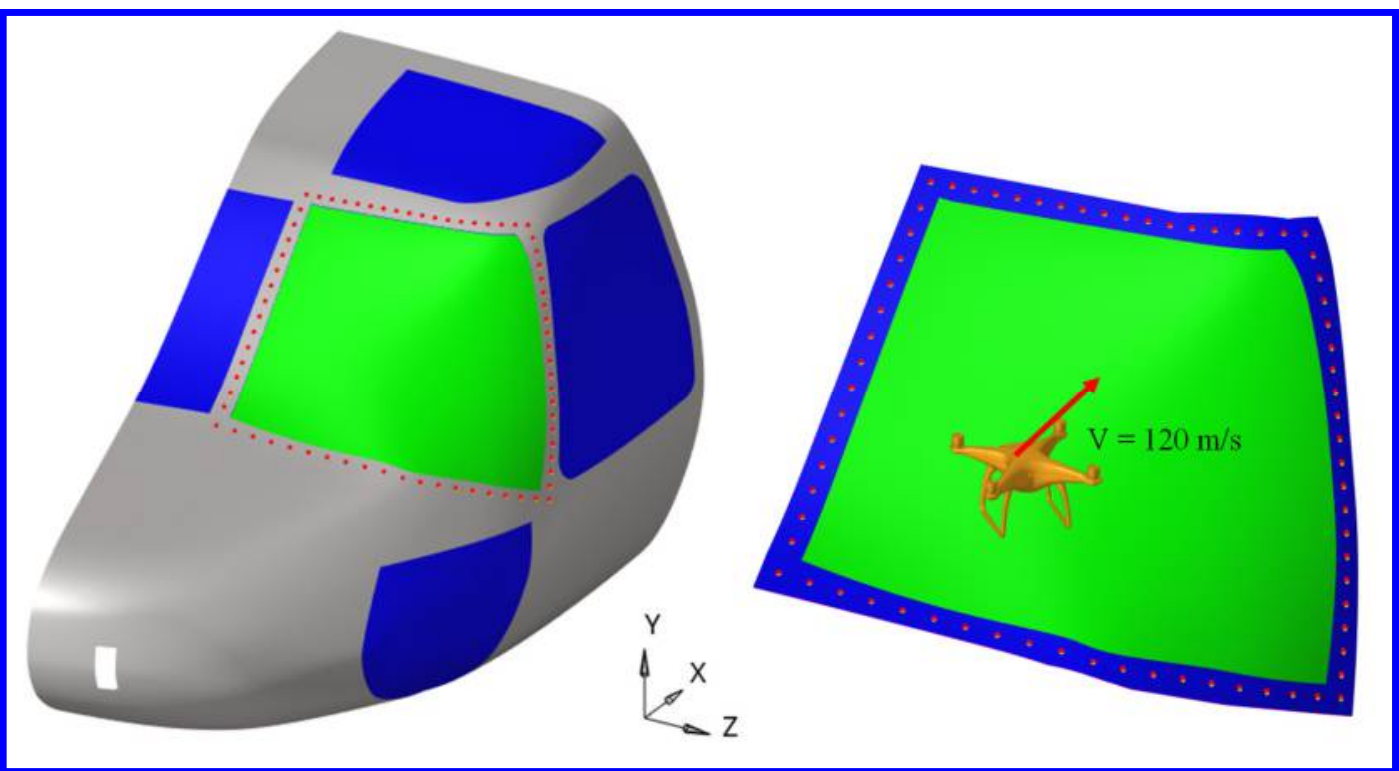

Figure 11: Realistic boundary conditions; including one half of the $H / C$ cockpit

First, the results from the simulations are compared using the base windshield wall thickness of 6 mm. Figure 12 compares the damage patterns of the simulation models. Here, the drone hits the windshield with the two motors positioned at the front and causes damage to the windshield in the impact area. The propagation of the damage occurs due to the impact of the drone body with the battery and the motors positioned at the rear. The deformation behavior of the windshields and the drones are very similar in hoth models

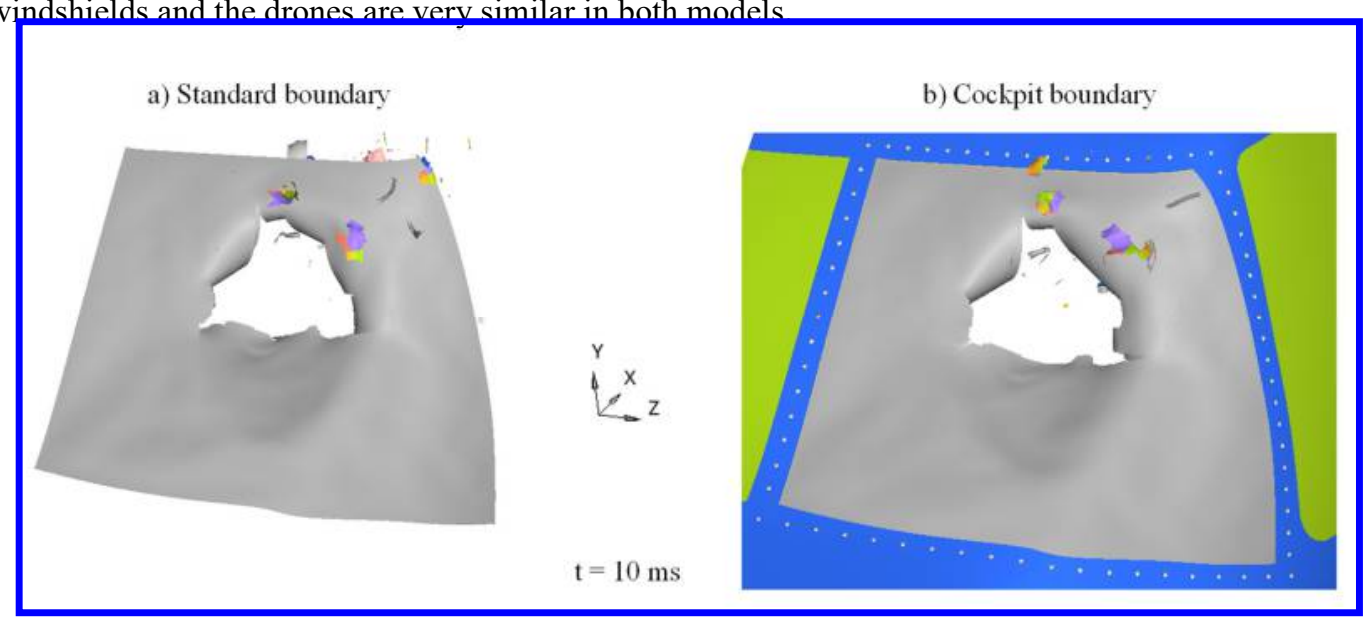

Figure 12: Damage of the windshield with different boundary conditions

In the next section, the results of the drone impact on the windshield with a wall thickness of $12 \mathrm{~mm}$ of the two simulation models are compared. It is investigated whether the helicopter windshield with a wall thickness of $12 \mathrm{~mm}$ is destroyed by the drone impact despite the windshield being attached to the cockpit structure via the bolted connection under worst-case conditions. Figure 13 shows the resulting damage of the drone impact on the windshield of the simulation models under worst-case conditions. Here, it is noticeable that the initial impact of the motors after 2 ms creates a small crack perforation in the cockpit model of the windshield. The perforation is small and is only caused by the impact of the motor positioned on the left. In contrast, this does not occur in the standard windshield model. The cockpit model with the realistic bolted connection of the windshield shows a larger damage due to the drone impact. It should be noted that the perforation of the windshield does not spread in the further course of the drone strike and thus no penetration of the windshield with damaged components of the drone body would be expected, because the drone is deflected towards the upper edge of the windshield. The basic windshield model shows a cracking along the boundaries, as it was already seen in Figure 10. The cockpit model allows a realistic damage image and a mapping of the kinematics of the drone impact. 
a) Standard boundary

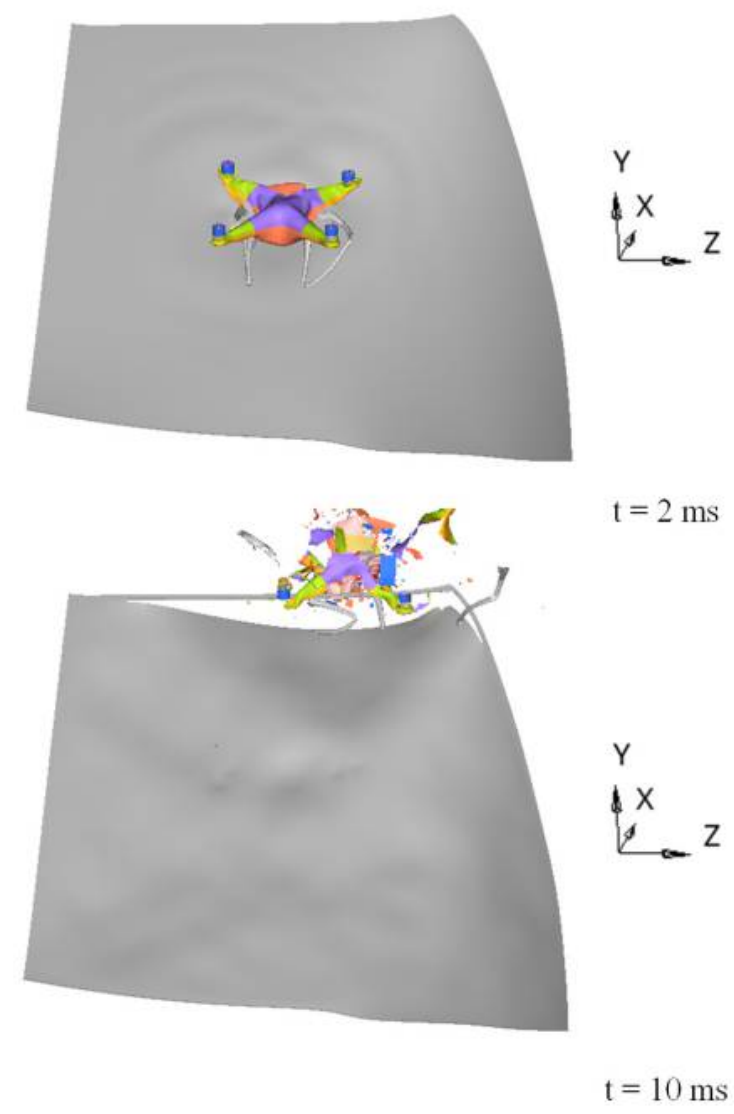

b) Cockpit boundary
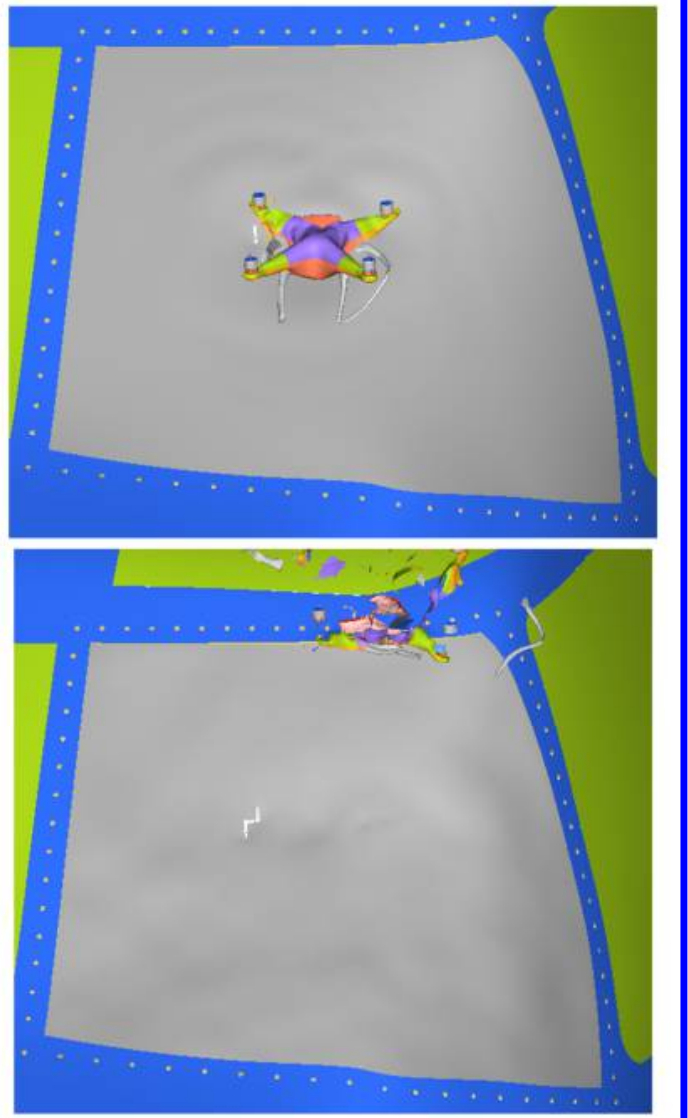

Figure 13: Damage of windshield for different boundary conditions with a thickness of $12 \mathrm{~mm}$

\section{Conclusion}

Drones are an increasing threat for manned aviation. Within this paper we investigated the mid-air collision of sUAVs with two aircraft target structures with numerical simulations. A generic wing leading edge as well as a helicopter windshield are used as target models. The projectile is a DJI Phantom 4 quadcopter UAV. This study has found that the projectile does not perforate the targets beneath $80 \mathrm{~m} / \mathrm{s}$ impact velocity. Higher velocities may lead to severe damage and possible accidents. Our investigations confirm that drones are able to perforate aircraft structures. With a velocity of $150 \mathrm{~m} / \mathrm{s}$, a drone may perforate the spar of a wing. Velocities between $80 \mathrm{~m} / \mathrm{s}$ and $150 \mathrm{~m} / \mathrm{s}$ lead to severe damage of the skin. The helicopter windshield is perforated at speeds above $90 \mathrm{~m} / \mathrm{s}$. The results show, that the boundary conditions have a significant influence on the impact and damage behavior. A fully clamped boundary condition develops cracks along the boundary. On the other hand, a realistic cockpit boundary conditions may develop cracks in the center of the target. Finally, we investigated the influence of the target thickness. The simulations show that even a doubling of the thickness can develop cracks in a worst-case scenario.

Taken together, these results suggest that drone strikes with aircraft structures must be avoided at all costs. Drone strikes have a large damage potential and are able to perforate aircraft structures with catastrophic consequences. Furthermore, UAVs should be designed for a minimal damage potential. Modifications to the aircraft structures in order to achieve a drone strike resistant design do not seem to be a practicable way forward, due to increasing costs and masses. The results show that the damage depends on the flight orientation of the UAV. This gives an opportunity in case of an unavoidable impact to reduce the damage by optimizing the flight orientation of the UAV and is a starting point for new research. 


\section{Acknowledgments}

This research work is financed by the German Federal Ministry of Education and Research within the funding program "Forschung an Fachhochschulen" under the contract sign DESIRE - 13FH581IX6.

\section{References}

[1] F. Franke, M. Schwab, U. Burger, and C. Hühne, "An Analytical Approach to Determine the Impact Force of Small Unmanned Aerial Vehicle Collisions with Rigid and Elastic Targets," in Proceedings of the 1. Aerospace Europe Conference 2020, Bordeaux, 2020.

[2] W. R. English, "National Transportation Safety Board Aviation Incident Final Report: DCA17IA202A," NTSB, Dec. 2017. Accessed: Sep. 19 2018. [Online]. Available: https://www.ntsb.gov/investigations/Pages/2017DCA17IA202AB.aspx

[3] A. Radi, "Potential damage assessment of a mid-air collision with a small UAV," Civil Aviation Safety Authority, Jun. 2013. Accessed: Oct. 4 2016. [Online]. Available: https://www.casa.gov.au/files/potentialdamage-assessment-mid-air-collision-small-rpapdf

[4] S. D. Cairns, L. A. Wood, and G. Johnson, "Volume I - UAS Airborne Collision Severity - Projectile and Target Definition,” Federal Aviation Administration, Dec. 2016. Accessed: Sep. 10 2020. [Online]. Available: https:// www.assureuas.org/projects/deliverables/a3/

Volume\%20I\%20UAS\%20Airborne\%20Collision\%20Severity\%20Projectile\%20and\%20Target\%20Definitio n.pdf

[5] O. Gerardo, L. Gomez, J. Espinosa, R. Baldridge, C. Zinzuwadia, and T. Aldag, "Volume II - UAS Airborne Collision Severity Evaluation: Quadrocopter," FAA, Springfield, UAS Airborne Collision Severity Evaluation 2, Jul. 2017. Accessed: Nov. 29 2017. [Online]. Available: http://www.assureuas.org/projects/deliverables/a3/ Volume\%20II\%20-\%20UAS\%20Airborne\%20Collision\%20Severity\%20Evaluation\%20-\%20Quadcopter.pdf

[6] O. Gerardo et al., "Volume III - UAS Airborne Collision Severity Evaluation: Fixed-Wing," FAA, Springfield, UAS Airborne Collision Severity Evaluation, Jul. 2017. Accessed: Nov. 29 2017. [Online]. Available: http:// www.assureuas.org/projects/deliverables/a3/Volume $\% 201 \mathrm{II} \% 20$ $\%$ 20UAS\%20Airborne\%20Collision\%20Severity\%20Evaluation\%20-\%20Fixed-wing.pdf

[7] K. D'Souza, T. Lyons, T. Lacy, and K. R. Kota, "Volume IV - UAS Airborne Collision Severity Evaluation: Engine Ingestion," FAA, Springfield, UAS Airborne Collision Severity Evaluation, Jul. 2017. Accessed: Nov. 29 2017. [Online]. Available: http:/www.assureuas.org/projects/deliverables/a3/Volume\%20IV\%20\%20UAS\%20Airborne\%20Collision\%20Severity\%20Evaluation\%20-\%20Engine\%20Ingestion.pdf

$\rightarrow[8]$ K. Schroeder, Y. Song, B. Horton, and J. Bayandor, "Investigation of UAS Ingestion into High-Bypass Engines, Part 2: Parametric Drone Study," in AIAA SciTech Forum, 58th AIAA/ASCE/AHS/ASC Structures, Structural Dynamics, and Materials Conference: American Institute of Aeronautics and Astronautics, 2017.

-[9] Y. Song, B. Horton, and J. Bayandor, "Investigation of UAS Ingestion into High-Bypass Engines, Part 1: Bird vs. Drone," in AIAA SciTech Forum, 58th AIAA/ASCE/AHS/ASC Structures, Structural Dynamics, and Materials Conference: American Institute of Aeronautics and Astronautics, 2017.

[10] Y. Song, K. Schroeder, B. Horton, and J. Bayandor, "Advanced Propulsion Collision Damage due to Unmanned Aerial System Ingestion," in 30th Congress of the International Council of the Aeronautical Sciences, Seoul, 2016.

[11] J. Bayandor, Y. Song, and K. Schroeder, "Crashworthiness for Aerospace Structures and Hybrids (CRASH) Lab Virginia Tech," Oct. 12016.

[12] M. H. Che Man, H. Liu, B. F. Ng, and K. Huat Low, "Preliminary Evaluation of Thrust Loss in Commercial Aircraft Engine due to Airborne Collision with Unmanned Aerial Vehicles (UAVs)," in 2020 International Conference on Unmanned Aircraft Systems (ICUAS), Athens, Greece, Sep. 2020 - Sep. 2020, pp. 1425-1432.

[13] M. Schwab, "Investigation of drone strike to jet engines: Preliminary experimental tests, test rig design and numerical analysis," Masterarbeit, Technische Hochschule Ingolstadt, Ingolstadt, 2020. Accessed: Sep. 202021. [Online]. Available: https://opus4.kobv.de/opus4-haw/frontdoor/index/index/start/0/rows/10/sortfield/score/ sortorder/desc/searchtype/simple/query/Schwab/docId/854

[14] T. Lyons and K. D'Souza, "Parametric Study of a Unmanned Aerial Vehicle Ingestion Into a Business Jet Size Fan Assembly Model," J. Eng. Gas Turbines Power, vol. 141, no. 7, p. 71002, 2019, doi: 10.1115/1.4042286.

[15] J. Yu et al., "Numerical simulation of a UAV impacting engine fan blades," Chinese Journal of Aeronautics, vol. 34, no. 10, pp. 177-190, 2021, doi: 10.1016/j.cja.2020.10.025. 
[16] N. D. Hou, "Dynamic Response and Damage of the Fan Blades during UAV Ingestion into an Aero-Engine," in Proceedings of the 32nd Congress of the International Council of the Aeronautical Sciences, Shanghai, 2021.

[17] H. Liu, M. Hasrizam Che Man, B. F. Ng, and K. H. Low, "Airborne collision severity study on engine ingestion caused by harmless-categorized drones," in AIAA Scitech 2021 Forum, VIRTUAL EVENT, 2021. Accessed: Jan. 19 2021. [Online]. Available: https://arc.aiaa.org/doi/10.2514/6.2021-1263

[18] M. H. Che Man and K. H. Low, "Damage Severity Prediction of Helicopter Windshields Caused by a Collision with a Small Unmanned Aerial Vehicle (sUAV)," in AIAA AVIATION 2021 FORUM, VIRTUAL EVENT, 2021.

[19] L. Jonkheijm, "Predicting helicopter damage caused by a collision with an Unmanned Aerial System using explicit Finite Element Analysis," Masterthesis, Technical University Delft, Delft, 2020. [Online]. Available: http://resolver.tudelft.nl/uuid:90105518-e3f8-4355-b9d3-bf541215e83c

[20] S. A. Ritt, F. Höfer, J. Oswald, and D. Schlie, "Drone Strike on a Helicoper Canopy Demonstrator," in Proceedings of the 47th European Rotorcraft Forum, Virtual, 2021.

[21] A. Dadouche, A. Greer, B. Galeote, T. Breithaupt, C. Vidal, and R. Gould, "Drone impact assessment on aircraft structure: windshield and leading edge testing and analysis," CR-GTL-2020-0054, Mar. 2020.

[22] X. Meng et al., "Dynamic response of the horizontal stabilizer during UAS airborne collision," International Journal of Impact Engineering, vol. 126, pp. 50-61, 2019, doi: 10.1016/j.ijimpeng.2018.11.015.

[23] X. Lu, X. Liu, Y. Li, Y. Zhang, and H. Zuo, "Simulations of airborne collisions between drones and an aircraft windshield," Aerospace Science and Technology, vol. 98, p. 105713, 2020, doi: 10.1016/j.ast.2020.105713.

[24] Y.-H. Wang, Z.-J. Wu, and M. Yang, "The Damage Prediction and Simulation for the UAV and Birdstrike Impact on Wing," Computer Simulation, no. 9, 42-45;83, 2018.

[25] T. Drumond, M. Greco, C. Cimini, and E. Medeiros, "Evaluation of Alternative Materials in a Wing Fixed Leading Edge to Support UAS Impact," in Proceedings of the XL Ibero-Latin-American Congress on Computational Methods in Engineering, Natal, 2019. Accessed: Oct. 9 2020. [Online]. Available: https:// www.researchgate.net/publication/338127339_EVALUATION_OF_ALTERNATIVE_MATERIALS_IN_A_ WING_FIXED_LEADING_EDGE_TO_SUPPי̄ORT_UAS_IMPACT

[26] T. Drumond, M. Greco, and C. Cimini, "Evaluation of Increase Weight in a Wing Fixed Leading Edge Design to Support UAS Impact," in Proceedings of the 10th Aerospace Technology Congress, October 8-9, 2019, Stockholm, Sweden, 2019, pp. 71-80.

[27] B. A. Warsiyanto, M. H. Widanto, I. Musthofa, and I. Maulana, "Dynamic response of the wing during UAV collision," Jurnal Teknologi Dirgantara, vol. 19, no. 1, pp. 79-92, 2021, doi: 10.30536/j.jtd.2021.v19.a3514.

[28] D. Ivančević, I. Smojver, and M. Leko, "Numerical Approach in the Evaluation of Aeronautical Structures Ballistic Protection," Transportation Research Procedia, vol. 35, pp. 190-199, 2018, doi: 10.1016/j.trpro.2018.12.029.

[29] Federal Aviation Administration., Battelle Memorial Institute., Columbus Laboratories., William J. Hughes Technical Center (U.S.), Department of Defense., and National Aeronautics and Space Administration., Metallic materials properties development and standardization (MMPDS): MMPDS-09, 2014.

[30] R. Hedayati, S. Ziaei-Rad, A. Eyvazian, and A. M. Hamouda, "Bird strike analysis on a typical helicopter windshield with different lay-ups," J Mech Sci Technol, vol. 28, no. 4, pp. 1381-1392, 2014, doi: 10.1007/s12206-014-0125-3.

[31] H. D. Hidallana-Gamage, D. P. Thambiratnam, and N. J. Perera, "Influence of Structural Sealant Joints on the Blast Performance of Laminated Glass Panels," J. Perform. Constr. Facil., vol. 29, no. 6, p. 4014151, 2015, doi: 10.1061/(ASCE)CF.1943-5509.0000646.

[32] Skylogic Research, 2018 Drone Market Sector Report: Opportunities and challenges in key market segments. [Online]. Available: http://droneanalyst.com/research/research-studies/2018-drone-market-sector-reportpurchase (accessed: Jan. 9 2019).

[33] M. Rodriguez-Millan, D. Garcia-Gonzalez, A. Rusinek, and A. Arias, "Influence of Stress State on the Mechanical Impact and Deformation Behaviors of Aluminum Alloys,” Metals, vol. 8, no. 7, p. 520, 2018, doi: 10.3390/met8070520.

[34] C. Lakshmana Rao, K. R. Y. Simha, and V. Narayanamurthy, Applied impact mechanics. Chichester, United Kingdom: Wiley, 2016. [Online]. Available: http://onlinelibrary.wiley.com/book/10.1002/9781119241829

[35] E. Sahraei, R. Hill, and T. Wierzbicki, "Calibration and finite element simulation of pouch lithium-ion batteries for mechanical integrity," Journal of Power Sources, vol. 201, pp. 307-321, 2012, doi: 10.1016/j.jpowsour.2011.10.094.

[36] Cogent Power Ltd, Electrical Steel Non Oriented Fully Processed. [Online]. Available: https:// perso.uclouvain.be/ernest.matagne/ELEC2311/T2006/NOFP.pdf (accessed: Mar. 11 2021). 
[37] MatWeb LLC, Overview of materials for Thermoset Polyurethane Foam, Unreinforced. [Online]. Available: http://www.matweb.com/search/DataSheet.aspx?MatGUID=91d44cae736e4b36bcba94720654eeae\&ckck=1 (accessed: Sep. 24 2021).

[38] University of Dayton, Risk in the Sky?, 2018. Accessed: Aug. 4 2021. [Online]. Available: https:// www.youtube.com/watch?v=7gt8a_ETPRE 